\title{
Male hypothyroidism-clinical relevance including role in reproduction
}

\begin{abstract}
Purpose: Overt Hypothyroidism is defined as arise of S.TSH $>10 \mathrm{mIU} / \mathrm{L}$. Since its incidence is more common in females one generally tends to ignore this diagnosis in males and usually the diagnosis is made in an emergency situation when the patient presents either with coma or with a severe form of Hashimoto's thyroiditis (HT) like IgG4 related thyroiditis.
\end{abstract}

Methods: A systemic literature search was performed using PubMed for all English articles till Sept 2014 regarding male hypothyroidism using MeSH terms like congenital hypothyroidism, male hypothyroidism and reproduction; subclinical hypothyroidism; Hoffmann's syndrome; myxedemic coma.

Results: To eradicate congenital hypothyroidism all over the world many countries have incorporated in their neonatal screening programme (NNSP), yet occasional cases of cretinism still get diagnosed .Important causes being genes encoding Transcription factor TTX1, TTX2 presenting as Bamforth syndrome, Thyroglobulin gene, Thyroid peroxidase (TPO), TSHR gene abnormalities, Pendreds syndrome coexisting with thyroid developmental abnormalities etc. Context Ig superfamily1deficiency (IGSF1), Fryns Anophthalmia Plus syndrome (APS), TSH $\beta$ gene deletion, frame shift mutation in first exon of Fibroblast growth factor8 (FGF8) can present as Central hypothyroidism. The first presentation maybe a neurological emergency like myxedemic coma either secondary to neurofibromatosis, lithium toxicity which responds to L-thyroxin or occasionally may not, responding only to steroids. Some patients may present as different forms of Hoffmann's syndrome or stiff leg syndromes. Subclinical hypothyroidis, (SH) and its aetiology along with TSH R mutations R109 Qreported as causation in 2 brothers and importance of treatment is highlighted. Importance of treatment of SH in children and adults is discussed. Mechanism of reversible kidney dysfunction in hypothyroidism is highlighted along with discussing its relationship with treatment. Changes in serum testosterone and gonadotropins are discussed in a patient of male hypothyroidism and the way it may affect reproduction.

Conclusion: Hypothyroidism may be the primary cause of a male presenting with Hypogonadotropic hypogonadism $(\mathrm{HH})$ and should be suspected in a man presenting with delayed puberty. Untreated hypothyroidism should be suspected as the cause of presentation of myopathies like Hoffmann Syndrome or other myopathies or myxedema coma. SH may warrant treatment in young males with known adverse affects on cardiovascular system although its affect on cognitive function has not been found especially in elderly.

Keywords: congenital hypothyroidism, ttx1, ttx2, central hypothyroidism, igsf1, hoffmann's syndrome, hypogonadotropic hypogonadism, male reproduction, myxedemic coma
Volume 2 Issue I - 2015

\author{
Kulvinder KK,' Gautam A,' Mandeep S² \\ 'Scientific Director, Centre for Human Reproduction, India \\ ${ }^{2}$ Consultant Neurologist, Swami Satyanand Hospital, India
}

Correspondence: Kulvinder Kaur, Scientific Director, Centre for Human Reproduction, 72I,G.T.B. Nagar, Jalandhar-14400 I, Punjab, India, Tel 9 II 81987204 3422, Fax 9 II8 I46| 3422, Email kulvinder.dr@gmail.com

Received: September 21, 2014 | Published: January 21, 2015
Abbreviations: HT, hashimoto's thyroiditis; HS, hoffmann syndrome; $\mathrm{AH}$, autoimmune hypothyroidism; $\mathrm{HH}$, hypogonadotropic hypogonadism; $\mathrm{SCH}$, subclinical hypothyroidism; $\mathrm{CH}$, congenital hypothyroidism; TG, thyroid gland; TPO, thyroid peroxidase; TSH, thyroid stimulating hormone; NNSP, neonatal screening programme; FMD, flow mediated dilatation; DC, coefficient of ddistensibility; NAFL, non-alcoholic fatty liver; CPK, creatine phosphokinase; APS, anophthalmia-plus syndrome; ES, empty sella; FGF8, fibroblast growth factor 8; H-P, hypothalamo-pituitary; $\mathrm{ACC}$, anterior cingulated cortex; EMG, electromyography; OSA, obstructive sleep apnea; $\mathrm{PH}$, pulmonary hypertension; IR, insulin resistance; MS, metabolic syndrome; CAC, coronary artery calcification; EIA, erythema ab igne; ATT, anti tubercular treatment; TBG, thyroxine binding globulin; DS, down's syndrome; $\mathrm{CeH}$, central hypothyroidism

\section{Introduction}

Although it is well known that hypothyroidism predominantly occurs in females, we have chosen the topic as "male hypothyroidism" as generally its importance gets ignored till the patient presents with a highly worsened disease with coma or severe form of disease or occasionally infertility, impotence or some kind of erectile dysfunction maybe the presenting symptom. To start with we would like to briefly review causes of hypothyroidism in general. Iodine deficiency remains the most common cause of hypothyroidism worldwide. In areas where iodine is sufficient, autoimmune disease (Hashimoto's thyroiditis (HT)) and iatrogenic causes are most common. 


\section{Causes of Hypothyroidism (Table I)}

Primary hypothyroidism: Primary hypothyroidism refers to hormone deficiency caused by intrinsic dysfunction of the thyroid gland that disrupts the synthesis and secretion of T4 and T3. Overt hypothyroidism is characterized by an elevated TSH levels, usually greater than $10 \mathrm{mIU} / \mathrm{L}$, in conjunction with a free $\mathrm{T} 4$ level below the lower level of normal reference range. In subclinical hypothyroidism, the TSH levels may be only moderately elevated, the free T4 levels remain in the low normal /normal range. When the condition is severe it is referred to as myxedema. Dietary iodine deficiency is an important cause in children in certain underdeveloped countries. The most important cause of primary hypothyroidism in developed countries is autoimmune or Hashimoto's thyroiditis, a condition in which altered $\mathrm{T}$ cell mediated immunity causes destruction of thyroid tissue. This may be a component of type 2 polyglandular autoimmune syndrome

Table I Genetic Causes of Congenital Hypothyroidism

\begin{tabular}{|c|c|c|}
\hline Defective gene protein & Inheritance & Consequences \\
\hline PROP-I & AUTOSOMAL RECESSIVE & $\begin{array}{l}\text { Combined pituitary hormone deficiencies with preservation of } \\
\text { adrenocorticotropic hormone }\end{array}$ \\
\hline \multirow{2}{*}{ PIT-I } & AUTOSOMAL RECESSIVE & Combined deficiencies of growth hormone \\
\hline & AUTOSOMAL DOMINANT & Prolactin, thyroid-stimulating hormone (TSH) \\
\hline TSHB & AUTOSOMAL RECESSIVE & TSH deficiency \\
\hline TTF-I (TITF-I) 12 & AUTOSOMAL DOMINANT & Variable thyroid hypoplasia, choreoathetosis, pulmonary problems \\
\hline TTF-2 (FOXE-I) ${ }^{13}$ & AUTOSOMAL RECESSIVE & Thyroid agenesis, choanal atresia, spiky hair \\
\hline PAX-8 & AUTOSOMAL DOMINANT & Thyroid dysgenesis \\
\hline TSH-RECEPTOR ${ }^{16}$ & AUTOSOMAL RECESSIVE & Resistance to TSH \\
\hline G (Albright hereditary osteodystrophy) & AUTOSOMAL DOMINANT & Resistance to TSH \\
\hline $\mathrm{Na}+/$-symporter ${ }^{19}$ & AUTOSOMAL RECESSIVE & Inability to transport iodide \\
\hline THOX2 & AUTOSOMAL DOMINANT & Organification defect \\
\hline Thyroid peroxidase ${ }^{14}$ & AUTOSOMAL RECESSIVE & Defective organification of iodide \\
\hline Thyroglobulin 15 & AUTOSOMAL RECESSIVE & Defective synthesis of thyroid hormone \\
\hline Pendrin ${ }_{(\text {SLC26A4) }}^{18}$ & AUTOSOMAL RECESSIVE & $\begin{array}{l}\text { Pendred syndrome: sensorineural deafness \&partial organification defect } \\
\text { in thyroid }\end{array}$ \\
\hline Dehalogenase I & AUTOSOMAL RECESSIVE & Loss of iodide reutilization \\
\hline
\end{tabular}

TSH, thyroid-stimulating hormone

Secondary hypothyroidism or central hypothyroidism: May be caused by a number of disorders that impair the hypothalamic-pituitary control of TG. Infiltrative disorders affecting the hypothalamus that can interfere with TRF secretion include sarcoidosis, hemochromatosis, and histiocytosis. Masses that impinge on the pituitary stalk can impede TRH delivery through the hypophyseal portal system. Compression of thyrotrophic cells by pituitary adenoma and other masses of sella turcica can inhibit synthesis and secretion of TSH. Surgery/radiotherapy used to treat pituitary adenoma can destroy thyrotrophic cells which lead to secondary hypothyroidism that can develop into pan hypopituitarism. Other women pituitary causes include lymphocytic hypophysitis, pituitary metastasis from primary malignant neoplasms, apoplexy, Sheehan's syndrome in women.

\section{Methods}

For this review we included data and relevant information obtained associated with autoimmune adrenal insufficiency and type 1 diabetes mellitus. It is less commonly a component of type 1 syndrome which includes adrenal insufficiency, panhypopituitarism and chronic mucocutaneous candidiasis. Other nonendocrine autoimmune conditions associated with autoimmune thyroiditis include atrophic gastritis, pernicious anemia, systemic sclerosis, sjogren's syndrome, celiac disease, and vitiligo. Individual's treated with interferon Alfa may develop autoimmune thyroiditis with transient or permanent hypothyroidism. Radioactive iodine therapy used for treatment for hyperthyroidism commonly destroys sufficient thyroid tissue to cause post ablative hypothyroidism. Exposure to certain pharmacologic and radio contrast dyes, some expectorants and topical disinfectants can disrupt thyroid function. Lithium inhibits secretion of T3 and T4 leading to hypothyroidism in $10 \%$ of people using the same. Other pharmacologic agents include stamuvidine, thallidomide, sutinitib and aminoglutethemide.
Consequences

Combined pituitary hormone deficiencies with preservation of

nocorticotropic hormon

ombined deficiencies of growth hormon

TSH deficiency

Thyroid agenesis, choanal atresia, spiky hair

Thyroid dysgenesis

Resistance to TSH

nification defect

through a PubMed database search for all articles published in English from 1950 upto 2014 which included the terms "male hypothyroidism," "subclinical hypothyroidism," congenital hypothyroidism", myxedema, cretinism and autoimmune hypothyroidism, Hoffmann syndrome.

\section{Results}

The electronic searches yielded a total; of 16,399 articles of which a total of 1648 were relevant to males. After ruling out the animal studies and the ones pertaining to female hypothyroidism and duplicate studies we finally selected 117 studies suitable for this review. No meta analysis was conducted.

\section{Autoimmune Hypothyroidism (AH)}

AH may be associated with a goiter (HT), or at later stages of the disease, minimal residual thyroid tissue (atrophic thyroiditis). Because 
the autoimmune process gradually reduces thyroid's function, there is a phase of compensation when normal TH levels are maintained by a rise in TSH. This state is called subclinical hypothyroidism (SH), though some patients might have minor symptoms. Later unbound T4 levels fall and TSH levels rise further and symptoms become more readily apparent at this stage (usually $\mathrm{TSH}>10 \mathrm{mIU} / \mathrm{L}$ ) which is referred to clinical or overt hypothyroidism. The mean annual incidence of $\mathrm{AH}$ is $4 / 1000$ women and 1/1000 men. It is more common in Japanese populations possibly due to genetic factors and chronic exposure to high iodine diet.

$\mathrm{Li}$ et al investigated IgG4 related thyroiditis in a surgical series of 70 patients with HT, 19 of whom immunostained positive for IgG4 This subgroup was characterized by a higher male: female ratio, more rapid progression and a higher level of circulating antibodies with no clinical evidence of other organ involvement concluding that IgG4 related thyroiditis constituted a distinct and more aggressive form of HT. ${ }^{1}$ A similar case of IgG4 related thyroiditis was presented in a 55year old male pilot by Salook et al. ${ }^{2}$ who presented with a previous history of hypothyroidism treated with L-thyroxin stabilized for several years with family history of hypothyroidism in his sister, admitted with history of pain in neck and feeling of pressure along with sub acute thyroiditis. He had a decreased TSH levels increased ESR, and CRP levels, along with very high antithyroid antibodies. Patient underwent hemithyroidectomy for pressure symptoms due to enlarging goiter. Diagnosis of IgG4 related thyroiditis got confirmed by elevated $\mathrm{IgG} 4-737 \mathrm{mg} / \mathrm{dl}$ ( $\mathrm{rr} 3-201 \mathrm{mg} / \mathrm{dl}$ ) and high $\mathrm{IgG} / \mathrm{igG}$ plasma cell ratio on immuno histochemistry. Hence they concluded IgG 4 thyroiditis and IgG-related disease should be considered in all patients with aggressive form of HT. ${ }^{2}$

\section{Congenital hypothyroidism}

\section{Definition and aetiopathogenesis}

Congenital hypothyroidism $(\mathrm{CH})$ is a common disease with a worldwide incidence of 1 in 3000-4000 newborns ${ }^{3}$ Permanent primary $\mathrm{CH}$ can be caused by abnormal thyroid differentiation (athyreosis), migration (ectopy) or functioning (leading to goitre formation). ${ }^{4}$ Goiters follow an autosomal recessive pattern of inheritance, whereas ectopy and athyreosis are considered as a singly sporadic activity with a family preponderance. Devos et al. ${ }^{4}$ studied 73 newborns over a period of nine years of which 230 had a permanent primary $\mathrm{CH}$. On scintigraphy scan 141 had ectopy (104girls), 38 had athyreosis (21 girls), 42 had goiter (18girls), 10 (3girls) had normal scan. Only in the ectopies was the proportion of girls significantly higher than $0.5(\mathrm{p}<0.0001)$, isolated cardiac malformations were observed in 7 patients $(3 \%)$ a prevalence 5 fold higher than in general population, this was largely due to ASD'Ss and VSD's which were only observed in ectopy and athyreosis. ${ }^{4}$

Thyroid gland (TG) development is orchestrated by the coordinated expression of several developmental transcription factors. Thyroid transcription factor 1 (TTF1, TTF2 and paired homeobox 8(PAX 8) are expressed selectively, but not exclusively in the TG. In combination, they dictate the thyroid cell development and the induction of thyroid specific genes such as thyroglobulin (Tg), thyroid peroxidase (TPO), the sodium iodide symporter ( $\mathrm{Na}+/ \mathrm{I}, \mathrm{NIS})$ and the TSH-receptor. Mutations in these developmental TF's or their downstream target genes are rare causes of thyroid agenesis or dyshormonogenesis, though the cause of most forms of congenital hypothyroidism remains unknown (Table1). Detection and treatment of congenital hypothyroidism $(\mathrm{CH})$ within the first few weeks of life will prevent the complications of this disorder. Since the clinical features of $\mathrm{CH}$ are subtle, many newborns remain undiagnosed at birth. ${ }^{5}$

\section{Incidence and sex ratio}

With the advent of screening of newborn populations using heel prick technique of Guthrie and Saunders the incidence of $\mathrm{CH}$ was initially reported in range of 1:1000 to 1 in 4000 newborns, ${ }^{6}$ neonatal screening is now performed in most developing countries. The incidence in USA has increased from 1:4094 in 1987 to 1:2372 in $2002{ }^{7,8}$ The reason for increased incidence although not clear has been attributed to change in testing strategy from cord blood to heel prick and with increased sensitivity and accuracy of TSH measurements as compared to thyroxin concentrations, many countries have switched from T4 follow up TSH approach to a primary TSH test. Dilli et al. ${ }^{9}$ studied from 2008-2010 for evaluation of national newborn screening programme 3223765 newborns where samples were collected by heel prick on a filter paper keeping a cutoff value for recall as $20 \mathrm{mU} / \mathrm{L}$ initially and $15 \mathrm{mU} / \mathrm{L}$ subsequently. They found that the mean annual incidence of possible $\mathrm{CH}$ showed a gradual increase over the years (1:888 in 2008, 1:529 in 2009 and 1:469 in 2010) with noting of regional differences. Male to female ratio was constant for all 3years being 1.04, 1.1, 1.1 and unlike all screening programmes where female preponderance is reported with a $2: 1$ female: male ratio, ${ }^{8}$ they did not find a female preponderance. ${ }^{9}$ One of the reasons for the female preponderance occurring is mostly in thyroid ectopy and occurs less with agenesis as given by a report from Canada. ${ }^{4}$ Similarly in Iran the female: male was $1: 1.4 .{ }^{10}$ Hence although they concluded an increased performance measures for $\mathrm{CH}$ screening in their neonatal screening programme (NNSP) the incidence of confirmed $\mathrm{CH}$ is not available in database at national level. In a study in Egypt, Bakhit 2013 found 79\% of permanent $\mathrm{CH}$ due to thyroid dysgenesis and dyshormonogenesis accounted for remaining $21 \%$ which was similar to results of Nair et al in India. ${ }^{11}$ Of 248 patients diagnosed with CH by NSP; 204(82.3\%) patients were diagnosed to have permanent $\mathrm{CH}$ and 14(17.7\%) transient $\mathrm{CH}$. As compared to other studies female to male ratio was 0.8 and 0.7 in permanent and transient $\mathrm{CH}$ respectively $161(65 \%)$ patients had thyroid dysgenesis (107 ectopic TG, 28 athyreosis and 26 thyroid dysplasia). $87(35 \%)$ patients had intact gland in thyroid scan and were considered to have dyshormonogenesis. Of these 87 patients 44 proved to have transient $\mathrm{CH}$ and 43 had permanent $\mathrm{CH}$ similar to worldwide reports. ${ }^{12}$ They concluded the slight higher incidence of transient $\mathrm{CH}$ in their study could be due to iodine deficiency and further difference in male: female ratio unlike earlier studies quoting higher female: male ratio, ${ }^{13,14}$ could be explained by higher incidence of parental consanguinity in that region and undiagnosed family history of $\mathrm{CH}$ as reported in study by Constanet et al. ${ }^{15}$

\section{Prevention}

Despite cretinism being completely eliminated in developed countries by early diagnosis of newborn screening programmes, a 22year old male was reported from Kolkata, India. This case presented as the most severe form of untreated $\mathrm{CH}$ presenting as the myxedematous form of cretinism along with mental retardation secondary to thyroid aplasia. He had stunted physical features with height- $83 \mathrm{~cm}$ (SDS-16.98) and weight $13.9 \mathrm{~kg}$ ( $<3 \mathrm{rd}$ percentile), along with severe stunted mental growth, delayed milestones, delayed bone (x-ray hands showing bone age $<$ 1year) and sexual maturation. ${ }^{16}$ Early diagnosis of either form of neurological/myxedematous cretinism should be attempted in case $\mathrm{CH}$ is not diagnosed initially. Treatment 
even in newborns is using thyroxine tablets, as liquid oral suspensions can't be depended on reliable dosing. Crushed T4 tablets, mixed with breast milk/formula milk is ideal and frequent monitoring every $2-3$ weeks is recommended during first months of life keeping infants with $\mathrm{CH}$ within the high end of range. ${ }^{17}$ Transplacental passage of maternal $\mathrm{TH}$ occurs before the fetal $\mathrm{TG}$ begins to function and provides partial TH support to a fetus with $\mathrm{CH}$. Early $\mathrm{TH}$ replacement in newborns with $\mathrm{CH}$ prevents potentially severe developmental abnormalities. $\mathrm{CH}$ may be transient, especially if the mother has TSH-R blocking antibodies or has received antithyroid drugs, but permanent hypothyroidism occurs in the majority. Neonatal hypothyroidism is due to TG dysgenesis in $80-85 \%$, to inborn errors of TH synthesis in $10-15 \%$, and is TSH-R mediated in $5 \%$ of affected newborns. Developmental abnormalities in males are half as compared to those in female newborns.

\section{Mutations}

Mutations that cause $\mathrm{CH}$ are increasingly being identified, but the vast majority remains idiopathic. Eg:

i. Salerno et al identified a heterozygous mutation of c.334G $>$ T on analysis of 3exons of TTF1, which results in replacement of glycine in position 112 with stop codon, generating a nonsense protein that lacks the correct transactivational domain in the C terminal region. Since NK2 homeobox 1(NKX2.1) gene encoding the TTF1 plays a critical role in lung, thyroid and CNS morphogenesis and function; mutations cause a rare form of progressive respiratory failure associated with surfactant synthesis, compositions and homeostasis. Hence concluding with the case report of this male child that screening for TTF1 deletions or mutations should always be considered in children with $\mathrm{CH}$ and unexplained neonatal respiratory distress or neuro developmental deficits. ${ }^{18}$

ii. Similarly Sandal et al reported Bamforth syndrome -a rare syndrome caused by mutations in the gene encoding TTF2, whose main features are $\mathrm{CH}$ due to thyroid dysplasia, cleft palate and spiky hair, with or without choanal atresia and bifid epiglottis and in this child additionally porencephaly was observed. ${ }^{19}$

iii. Mutations in the thyroid peroxidase (TPO) gene are the most common cause for dyshormonogenesis. So far more than 80 mutations in the TPO gene have been described, resulting in variable decrease in TPO bioactivity. Clinically these TPO defects manifest with congenital primary goitrous hypothyroidism. Altmann et al. ${ }^{20}$ reported 2 German children with $\mathrm{CH}$ who were identified to have compound heterozygous TPO mutations. They both shared the same novel mutation in the TPO gene (C756R) in exon 13. One case presented with an apparently dominant inheritance of thyroid dyshormonogenesis. ${ }^{20}$

iv. Similarly $\mathrm{CH}$ due to thyroglobulin (TG) deficit, an autosomal recessive disease (OMIM\#274700) was reported in 2 sisters born from consanguineous parents, but the father's (euthyroid) analysis showed that he was a heterozygous carrier of the novel point mutation of the TG gene determining a stop codon at 768 of the protein identified in the 2 sisters. ${ }^{21}$

v. A nonsense mutation (W520X) was identified in a child in the third transmembrane domain of the TSHR that causes the lack of the $\mathrm{C}$ terminus portion of the receptor. Moia et al. ${ }^{22}$ concluded that the mechanism through which W520X mutation exerts its effects is more likely to be haploinsufficiency rather than a dominant effect, which could explain the phenotype of their patient, having a hormonal pattern of a mild subclinical hypothyroidism without overt disease phenotype. ${ }^{22}$

vi. In humans PAX8 gene maps to chromosome 2q12-q14 and consists of atleast 10exons. So far several PAX8 mutations and a rare sequence variant had been reported, in patients with hypoplastic normally located TG associated with renal anomalies. But Vincenzi et al. ${ }^{23}$ studied a male patient of hypothyroidism with his family members presenting with various phenotypes varying from $\mathrm{CH}$ to just subclinical hypothyroidism and the genetic variant R133W-PAX8 was not directly involved in the development of the thyroid phenotype. ${ }^{23}$

vii. Recently by exomic sequencing Kuhnen et al. ${ }^{24} 2014$ unexpectedly identified mutations in patients with structural thyroid defects (p.Leu597Ser) and (p. Gln 413 Arg); the latter patient in addition having severe hearing loss; both missense homozygous mutations in SLC 26A4 gene, both mutations which were previously described as loss of function mutations in patients with Pendred syndrome and nonsyndromic enlarged vestibular aqueduct. Thus they suggested extending analysis to DLC 26A4 in patients with apparent thyroid dysgenesis. ${ }^{24}$ Montanelli et al. ${ }^{25}$ described late onset goiter and a novel mutation in sodium iodide symporter of the proband and family members of a 16yr old girl inherited from her parents and recommended that thyroid ultrasonography be performed in $\mathrm{CH}$ patients with low radioactive iodine uptake and elevated serum $\mathrm{Tg}^{25}$

\section{Long term consequences}

Long term follow up of $\mathrm{CH}$ is of particular interest. $\mathrm{CH}$ is an umbrella term for several congenital thyroid disorders usually characterized by pathologically low concentrations of thyroxine that may or may not be accompanied by elevated concentrations of thyroid stimulating hormone (TSH), TH's act on such processes as neuronal migration and differentiation, myelination, and synaptogenesis, which are essential for proper neurodevelopment and are also involved in maintainance of normal physiological function s such as bone maturation. Pathologically low concentrations of TH's experienced during critical stages of development may cause severe mental retardation and skeletal growth abnormalities. ${ }^{26-29}$ The deleterious outcomes of untreated $\mathrm{CH}$ are well known. ${ }^{30-33}$ In a long term follow up study on hearing since neonatal period Lichtenberger et al ${ }^{34}$ found hearing loss to be three times higher than the reference population. Hearing impairment was diagnosed at a median age of 7 (25th and 75 th percentile $34-19 y r s) 17 \%$ of affected patients required hearing support in early adulthood. Hearing loss was associated with type of $\mathrm{CH}$ (patients with athyreosis and gland in situ were more frequently affected than that with an ectopic TG, with disease severity as assessed by bone maturation delay at the time of diagnosis with atleast one knee epiphyseal ossification center absent in the most severe form and with other associated chronic diseases. Hearing loss was mostly bilateral (90\%), mild to moderate (96\%), of the sensorineural type (76\%) and concerned high or very high frequencies. Hence they concluded that despite major improvements in prognosis, hearing loss remained a significant problem particularly in patients with severe $\mathrm{CH}$. With parents and primary care physicians being aware of this risk, early diagnosis and intervention could improve long term prognosis of these patients. ${ }^{34}$ 
With rapid institution of high dose levothyroxine $10-15 \mu / \mathrm{Kg} /$ day producing prompt normalization of thyroid function, Albert et al. ${ }^{35}$ found normal intellectual and motor development in $54 \mathrm{CH}$ cases and 53 control siblings aged $9.6+/-3 y$. They found that severity of $\mathrm{CH}$ did not influence outcome but greater time to normalize free T4 was associated with worst motor balance. Therefore they suggested that subtle negative impact on motor function associated with time to normalize free T4 levels is consistent with benefit from rapid initial correction ${ }^{35}$ whereas Bongers-Schokking suggests that $\mathrm{CH}$ overtreatment during first 2 years leads to lowered cognitive outcomes at 11 years whereas under treatment if not complicated by over treatment results in normal cognitive development and that fast TSH normalization at initial treatment leads to above developmental scores at a younger age but affect IQ at age $11 .{ }^{36}$ Bagatti $\mathrm{N}$ et al. ${ }^{37}$ studied the requirement of L-T4 in 36 patients ( 27 females/9 males), where 13 had $\mathrm{CH}$ (athyreosis), while rest 23 had acquired hypothyroidism (AH, $\mathrm{n}=14$ due to previous thyroid nodule, $\mathrm{n}=9$, thyroid carcinoma) found a higher requirement (dose $/ \mathrm{kg}$ ) in $\mathrm{CH}$ as compared to $\mathrm{AH}$ despite a higher TSH in adult patients. They proposed that the difference in requirement of replacement therapy between adult patients of $\mathrm{CH}$ and those with surgical athyroidism could be explained by a lack of TH's since fetal life in $\mathrm{CH}$ which could determine a different set point of the hypothalamic-pituitary-thyroid axis. ${ }^{37}$ Young adults with $\mathrm{CH}$ treated with long term L-T4 replacement therapy may have significant impairment of flow mediated dilatation (FMD) and brachial; artery distensibility with the measurement of coefficient of distensibility (DC). Oliviera et al. ${ }^{38}$ studying 32 young adults with $\mathrm{CH}$ aged 18.9 and 32age/sex matched controls suggested that high TSH levels, inadequately corrected by L-T4 replacement therapy, especially during puberty, can exert significant effects on the elastic and functional vessel properties. ${ }^{38}$

The importance of treating primary hypothyroidism is revealed by the first report in a 27 year old man with chronic untreated primary hypothyroidism who presented with delayed puberty, marked short stature (ht- $133 \mathrm{~cm})$ with severe almost continuous headache for last 6years. MRI revealed pituitary hyperplasia. This patient was diagnosed as primary hypothyroidism at $21 \mathrm{yrs}$ age and L-T4 therapy lead to resolution of symptoms and a gain in height of $28 \mathrm{~cm}$ over 6years. Evaluation for lack of pubertal progression along with chronic nausea, vomiting, fatigue and weight loss revealed secondary hypocorticolism (at $9 \mathrm{am}-4.8 \mu \mathrm{g} / \mathrm{dl}, \mathrm{ACTH}-3.2 \mathrm{pg} / \mathrm{ml}$, GH deficiency (IGF1-65ng/ml (RR-117-325ng/ml) and HH (9AM Testosterone98ng/dl (RR-280$1500 \mathrm{ng} / \mathrm{dl})$ LH-.01 (1.14-5.75miu/l) with empty sella (ES)on MRI brain. Uncontrollable thyrotroph hyperplasia due to chronic untreated primary hypothyroidismx 15years may have been damaging adjacent corticotrophs, gonadotrophs leading to panhypopituitarism and ES. ${ }^{39}$

\section{Other causes of male hypothyroidism}

\section{Central Hypothyroidism}

I. Context Ig superfamily member 1 (IGSF 1) deficiency was recently discovered as a novel $\mathrm{X}$ linked cause of central hypothyroidism $(\mathrm{CeH})$ and macroorchidism. Joustra et al. ${ }^{40}$ studied 24 males from 10 families examined in university of Leiden, Amsterdam, Cambridge and Milan. 17 index cases showed $\mathrm{CeH}$ (100\%), Hypoprolactinaemia ( $\mathrm{n}=16.67 \%)$ and transient partial GH deficiency $(n=3.13 \%)$. Pubertal testosterone production was delayed, as were the growth spurt and pubic hair development. However testicular growth started at a normal age and attained macro orchid state size in all evaluable adults. BMI, percent fat and waist circumference tended to be elevated. Metabolic syndrome was present in 4 out of 5 patients in 55year age. Heterozygous female carriers (32-80yrs) also showed $\mathrm{CeH}(6 / 18,33 \%)$, hypoprolactinaemia in $2(11 \%)$ and no case of GH deficiency. Thus they concluded that male patients in IGSF1 deficiency is characterized by $\mathrm{CeH}$, hypoprolactinaemia, delayed puberty, macroorchidism and increased body weight. A subset of female carriers also exhibit $\mathrm{CeH} .{ }^{40}$ Further Nakamura et al ${ }^{41}$ studying 4 Japanese boys with congenital $\mathrm{CeH}$ found 3 novel IGSF1 mutations. In patients $1 \& 2$ p.R1189X, and patient 3 and 4 distinct missense (p.V1082E) or nonsense (p.Q645X) mutations in IGSF. The mothers of patientsc1, 3 and 4 were heterozygous for these mutations which provides additional genetic evidence that loss of function mutations in IGSF1 causes an Xlinked C-CeH and variable prolactin deficiency. ${ }^{41}$

II. Fryns Anophthalmia-Plus syndrome(APS) was reported in a 3 year old child by Cayir et al. ${ }^{42}$ who presented with central hypothyroidism, chiari type 2 malformations, conductive hearing loss and developmental regression. He had asymmetry of face and head, left choanal atresia, a sunken facial appearance microphthalmia in left eye, severe microphthalmia in left eye, bilateral low set ears scarring from cleft palate surgery. MRI revealed decreased right globe volume, an undeveloped left globe, decreased left optic nerve thickness, chiari type 2 malformations and left choanal atresia. Summary of the presented case reported here and 14 previous cases might be defined as APS. ${ }^{42}$

III. Hermann et al. $^{43}$ reported a novel deletion in Thyrotropin $\beta$ subunit gene identified by array comparative genomic hybridization $(\mathrm{aCGH})$ analysis as a cause of isolated central $\mathrm{CH}(\mathrm{ICCH})$ in a 51days old boy originating from Turkey. Acgh using specific probes around TSH $\beta$ gene showed him to be homozygous for a $6 \mathrm{~kb}$ deletion spanning all exons and parts of 5'UTR of the gene. Thus they concluded infants clinically suspected of hypothyroidism should be evaluated thoroughly even if TSH based screening is normal. In cases with ICCH and undetectably low TSH serum concentrations, a TSH $\beta$ gene deletion should be considered and aCGH should be performed. ${ }^{43}$

IV. Suzuki et al. ${ }^{44}$ reported a De novo frame shift heterozygous p.S192fsX204 mutation in last exon of fibroblast growth factor 8(FGF8) in a patient who presented with gonadotropin deficiency with multiple malformations with primary hypothyroidism, with micropenis, craniofacial anomalies and ventricular septal defect at birth. Patient examined at 8 months and 16years of age revealed delayed puberty, hyposmia, borderline mental retardation and, mild hearing difficulties. Thus concluding that frame shift mutations in FGF8 can account for the etiology of hypothalamo-pituitary (H-P) dysfunction. ${ }^{44}$

$\mathrm{V}$. $\mathrm{CeH}$ is generally related to a H-P disorder or arising as an iatrogenic condition. Usually it is difficult to diagnose $\mathrm{CeH}$ because it lacks specific change clinical signs and they may be masked by other pituitary hormone deficiencies. Treatment is with L-T4 replacement therapy after exploration of circadian TSH cycle index and confirming diagnosis of low free T4 with low/normal or mildly increased TSH levels. ${ }^{45}$ Similarly patients with thalassemia major present with $\mathrm{CeH}$ by age of 18 with equal incidence in both sexes. ${ }^{46} \mathrm{CeH}$ and hypogonadism was part of the presenting complaint of a stage IV small cell 
carcinoma along with secondary adrenal insufficiency in a 66 year old man who was a chronic smoker. ${ }^{47}$

\section{Neurological}

I. Myxedemic coma in a patient with neurofibromatosis has been reported, in a 51year old male to reverse with thyroid hormone replacement therapy and other additional measures in shock and hypoventilation. ${ }^{48}$ Also a case of primary hypothyroidism with deteriorating consciousness that did not respond to thyroxine and ultimately responded to steroids was reported in a 60year old male and was diagnosed as a case of Hashimoto's encephalopathy. ${ }^{49}$ In addition lithium induced toxicity and myxedemacrisis has been reported in a 70year old male subject on lithium for bipolar disorder, hence emphasizing the importance of monitoring thyroid function tests in patients on lithium therapy. ${ }^{50}$

II. Experimentally PET Scans examining glucose metabolism in 13 hypothyroid subjects with 10 healthy controls show lower regional activity in the amygdale, hippocampus and perigenual anterior cingulated cortex (ACC), left subgenual ACC, and right posterior cingulated cortex and this activity corrects after thyroxine replacement. ${ }^{51}$

III. Thyroid disorders can present with varied neurological manifestations affecting the entire neuraxis. Hypothyroidism can present as coma ${ }^{48,52}$ when it involves the brain and at the other end of the spectrum can produce neuropathies and myopathies, when it involves the peripheral nerves and muscles. It may resemble polymyositis. Rarely, stiffness and tautness of muscles may be the only manifestation of hypothyroidism. Sowmini et $\mathrm{al}^{53}$ reported a 30year old young male who presented with generalized muscle stiffness, involving the limbs, facial and paraspinal muscles. The stiffness was so severe that it restricted all daily activities and increased progressively with movements and produced recurrent falls. This clinical picture resembled one of stiff person syndrome. Since he had hypertrophy of calf muscles and generalized muscle tautness a differential diagnosis of Hoffmann's syndrome or other disorders which resemble stiff person syndrome was ruled out. Investigations revealed severe hypothyroidism with elevated thyroid antibodies. Importance of identifying such a condition is because it is completely treatable with thyroid replacement therapy and this patient could lead normal life following treatment. ${ }^{53}$

IV. Myopathic changes are observed in $30-80 \%$ of patients with hypothyroidism. ${ }^{54}$ Patients with more severe or longstanding untreated hypothyroidism are more likely to develop clinically significant muscle disease. Slowed muscle contractio, in hypothyroid myopathy, may be caused by a shift in the distribution of muscle fiber types from fast-twitch to slow twitch fibres. A reduction in muscle mitochondrial oxidative capacity and $\beta$-adrenergic receptors, as well as the induction of an insulin resistant state, may result in these changes. ${ }^{55}$ The global inhibition of the main oxidative pathways (substrate incorporation, substance oxidation) and of the respiratory chain within cells may also cause myopathic symptoms. ${ }^{56}$ There are four variants of hypothyroid myopathy known as Hoffmann Syndrome, Kocher-Debre-Semelaigne syndrome, atrophic form and myasthenic syndrome..$^{57,58}$ Hoffmann syndrome (HS) is a rare form of hypothyroid myopathy in adults characterized by presence of muscle weakness, stiffness and pseudo hypertrophy. Senanayke et al. ${ }^{59}$ reported a 39 year old male with primary hypothyroidism diagnosed at childhood and not on regular thyroxine therapy who presented with fatigue, cold intolerance, constipation, exertional breathlessness, progressive muscle weakness and swelling of the legs for one year. Examination revealed pseudo hypertrophy of calf muscles with marked symmetrical proximal upper and lower limb weakness. His TSH and creatine phosphokinase (CPK) were significantly elevated and electromyography (EMG) was compatible with myopathic disorder. After institution of thyroxine therapy his weakness improved markedly and pseudo hypertrophy regressed in two months. ${ }^{59}$ Besides that a rare case of HS was reported in a 12year old male child along with pituitary hyperplasia. This child presented with headache, besides the other features with which HS patients present. Bilateral papilloedema was present and MRI revealed enlargement of pituitary glands and Hashimoto's thyroiditis was confirmed on thyroid studies. Treatment with TH's resulted in complete improvement of symptoms in three months. ${ }^{60}$ Two cases of long duration HS were reported by Nalini et al. ${ }^{61}$

\section{Miscellaneous}

\section{Autoimmune}

a) Cetinkaya et $a 1 .^{62}$ reported a rare association of monosomy $18 \mathrm{p}$ Syndrome in a $34 y$ year old male subject who presented with polyglandular autoimmune (PAS) Type III A. The patient presented with mental retardation, short stature, wide earlaps, old looking face atrophic mouth, drooping cheeks with full teeth loss and weak, soft sparse hair. Chromosome analysis revealed 46XY, del 18(p11,2). He was also found to have autoimmune thyroiditis, primary hypothyroidism, diabetes mellitus type 1 besides GH deficiency and hypogonadotropic hypogonadism. ${ }^{62}$

b) Mostly hypothyroidism is autoimmune, but a rare case is reported of a 2year old boy of ulcerative colitis on sulfasalazine therapy that subsequently developed type1 diabetes mellitus, autoimmune hepatitis and autoimmune hypothyroidism. This highlights the role of immune related mechanisms in the pathophysiology of disease like ulcerative colitis. ${ }^{63}$

c) Hypothyroidism had been part of polyendocrinopathy syndrome in a $27 \mathrm{yr}$ old boy who presented with reversible adrenal insufficiency with hypothyroidism with falsely raised TSH because of presence of heterophilic antibodies. ${ }^{64}$

d) Recent data have shown a relationship between obesity and thyroid autoimmunity, with the adipocyte hormone leptin appearing to be the key factor linking the two conditions. Duntas et al..$^{65}$ explain how leptin has variably been implicated in thyroid function, while recent findings suggest that leptin resistance may mitigate leptin deficiency and enhance autoimmunity in obese subjects via mechanisms operating independent of thyroid function. The development of resistance to the weight lowering effects of leptin in obesity may well be initiated by activation of inflammatory signaling which substantially contributes to the derangement of immune response and propagation of autoimmunity in susceptible individuals. Thus they concluded that the regulation of inflammasome derived cytokines in obesity is an important step in controlling the trigger of thyroid autoimmunity. The 
clarification of the pathways may offer innovative therapeutic targets in obesity as well as thyroid autoimmunity. ${ }^{65}$ Further Rotondi et al. ${ }^{66}$ on the basis of study of 55 morbidly obese (BMI $>40 \mathrm{KG} / \mathrm{M} 2$ ) and 55 nonobese with raised TSH concluded that the impact of raised S.TSH on the lipid profile differs in morbidly obese as compared to nonobese patients, suggesting that obese patients might not be truly hypothyroid. Measuring total cholesterol could be a helpful tool for deciding whether a morbidly obese patient with a raised serum TSH should be given levothyroxine treatment or not. ${ }^{66}$

e) In assessing the relation of non-alcoholic fatty liver (NAFL) disease with insulin resistance (IR), metabolic syndrome (MS) and hypothyroidism Misra et al. ${ }^{67}$ studied 40 cases of NFALD with 30 controls. He found that NAFLD patients demonstrated significantly higher IR, TSH values and a significantly lower FT4 levels as compared to controls, demonstrating prevalence of IR and hypothyroidism in patients. A significant positive correlation between TSH and IR and a negative correlation between FT4 and IR were established in the cases. Moreover TSH was significantly related to LDL-cholesterol, independent of IR. Hence earlier detection of risk factors in NAFLD coexisting with hypothyroidism maybe helpful in preventing cardiovascular diseases. ${ }^{67}$ Similarly Posadas et al. ${ }^{68}$ studied 753 patients ( $45 \%$ males, aged $\left.35-70 y r s\right)$ with no history of DM, renal, Sub clinical hypothyroidism $(\mathrm{SCH})$ was defined as raised TSH with normal free T4 levels, coronary artery calcification and abdominal visceral obesity defined by computed tomography. They found $\mathrm{SCH}$ was present in $17.7 \%$ of studied population. The prevalence of fatty liver (FL) was similar in euthyroid and $\mathrm{SCH}$ subjects $(31.8 \%$ vs $27.8 \%$.But FL with SCH patients were heavier and had more metabolic abnormalities as compared to $\mathrm{SCH}$ plus normal liver subjects. SCH along with FL was associated with MS, IR and coronary artery calcification (CAC) independent of potential confounders. ${ }^{68}$ Although overt and $\mathrm{SCH}$ are risk factors for atherosclerosis. Zhang et al. ${ }^{69}$ found increased coronary artery disease with greater degree of CAC in a large cohort study of 41403 euthyroid subjects as well. Dahiya et al. ${ }^{70}$ estimated nitric oxide and ischemia modified albumin in 50 newly diagnosed patients of hypothyroidism and found it to be significantly raised in hypothyroid patients as compared to controls. Hence they concluded that estimation of nitric oxide and ischemia modified albumin (markers of oxidative stress) in hypothyroidism may help to throw light on pathogenesis and severity of the disease although further research is needed to establish their role as biomarkers in hypothyroidism. ${ }^{70}$

f) The acute Wolff Chaikoff effect ${ }^{71,72}$ suggests that iodine induced hypothyroidism especially in patients with amiodarone therapy is caused by a chronic acute inhibition of thyroid gland..$^{73,74}$ Although till recently it was not clear how excessive iodine use is linked to thyroid autoimmunity. Latrofa et al. ${ }^{75}$ answered the question by studying thyroglobulin auto antibodies (TgAb) epitopes in 16 iodized salt (IS) users out of 906IS users and 17 IS nonusers (of389IS-nonusers) by inhibition binding assay to $\mathrm{Tg}$ using human monoclonal TgAb-Fab directed to A, B, C and $\mathrm{D}$ epitopes on $\mathrm{Tg}$ and found a significantly higher iodine excretion in IS users with TgAb and not TPOAb more frequent in IS users. HT ultrasound to identify thyroid hypoechogenicity was found in 87 patients and $\mathrm{TgAb}$ directed to the epitope B of $\mathrm{Tg}$ were more frequent in IS users than IS nonusers and they concluded Iodine induced thyroid autoimmunity is related to $\mathrm{TgAb}$ and the unmasking of a cryptic epitope on $\mathrm{Tg}$ contributes to this relationship in humans. ${ }^{75}$

\section{Other miscellaneous}

A) Consumptive hypothyroidism is a rare condition, usually described in association with diffuse infantile haemangioma of the liver, over expressing type 3 iodothyronine deiodinase. DeCorti et al ${ }^{76}$ reported a case of acquired hypothyroidism associated with a parotid haemangioma in a male child who was initially evaluated at 48 days of age due to persistent jaundice. Despite replacement therapy, resolution of clinical and hormonal characteristics occurred only after introduction of propranolol at 3 months of age to the therapeutic regimen. In their review of literature they only found one case of proven consumptive hypothyroidism associated with infantile parotid haemangioma, thus concluding how underestimated it maybe and it should be considered a real possibility if infantile parotid haemangioma found. ${ }^{76}$

B) Erythema ab igne (EIA) is a dermatosis characterized by reticulate red brown pigmentation and telangiectasia resulting from long term exposure to infra red irradiation. Turan et al. ${ }^{77}$ also reported a 42 year old male, who presented with red brown spots and blisters on both thighs and behind legs. He was diagnosed with EAI based on clinical, historical and histopathological features presented and they concluded that a final diagnosis of bullous EAI associated with normocytic normochromic anemia and subclinical hypothyroidism was the presenting feature of this case preferring hot environments. ${ }^{77}$

C) Obstructive sleep apnea (OSA) and hypothyroidism are two diseases that can be associated with pulmonary hypertension $(\mathrm{PH})$. Studying the effect of combination of hypothyroidism with OSA Araz et al. $^{78}$ found that the combination of hypothyroidism with OSA is associated with an increased frequency and severity of $\mathrm{PH}$. When $\mathrm{PH}$ is found out of line with the severity of OSA, thyroid dysfunction should be investigated. Of the 236 patients studied 167 were male and69 female participants-of which Group I was OSA with $81.9 \%(\mathrm{n}=149)$ males, Group II ( $\mathrm{n}=56,44.6 \%$ males) only hypothyroidism while Group III $(n=31,64.6 \%$ males where both hypothyroidism and OSA present. ${ }^{78}$

D) In a study on HIV infected patients coinfected with multidrug resistant tuberculosis receiving antitubercular treatment (ATT) and antiretroviral treatment, Andries et al. ${ }^{79}$ found hypothyroidism to be a common side effect of patients receiving ethionamide, $\mathrm{p}$-amino salicylic acid and stavudine in a study conducted in Mumbai ,India. $61 \%$ of the 116 patients enrolled in this study from Oct 2006-Mar 2013 were male of which $37 / 69(54 \%)$ had hypothyroidism after atleast 90days of treatment. Co administration of PAS and ethionamide was found to double the risk of hypothyroidism. Therefore they recommended to screen at baseline, 3months, 6months and then every 6monthly thereafter for HIV infected persons on MDR-TB treatment containing PAS and/or ethionamide until newer safer and more efficacious MDR-TB regimens become available. $^{79}$

E) In a cross sectional retrospective study Hadlow et al..$^{80}$ analyzed TSH and free T4 results from 152261 subjects collected over 12 years by a single laboratory and found the relationship 
between $\log$ TSH and free T4 was nonlinear. For free T4 within reference the reference range $(10-20 \mathrm{pmol} / \mathrm{l})$ median TSH was higher in men than in women and increased across age bands with the highest values in those 80years and older $(\mathrm{p}<0.001)$. In contrast in overt hypothyroidism $(n=4403) \mathrm{TSH}$ was lower in older age groups than in those aged 20-39years and thus concluded that the TSH-freeT4 relationship is not inverse log-linear but can be described by 2 overlapping negative physiological curves. At physiological free T4 concentrations, TSH is higher in men, and in older people, whereas the TSH response to hypothyroidism is more robust in younger people. ${ }^{80}$

F) Although hyperprolactinaemia due to hypothyroidism is known to result in gynecomastia in adults, this observation is not seen in prepubertal children. Dayal et al. ${ }^{81}$ reported a boy who developed gynecomastia after the first year of age and was later diagnosed to have $\mathrm{CH}$ along with hyperprolactinemia. ${ }^{81}$

G) Kyrysiak et al. ${ }^{82}$ reported different effects of methyl testosterone administration on thyroid function in 2 twin brothers with transient hyperthyroidism developing in one of the brothers with hypothyroidism following methyl testosterone (a non aromatizable androgen). MT resulted in a marked reduction of thyroxine binding globulin (TBG), irrespective of the patients hormonal status whereas the impact on free TH's depended on baseline thyroid function. They concluded that in any hypothyroid patient receiving levothyroxine in whom TH's suddenly change without any apparent reason use of non aromatizable androgen or any other drugs which affect TBG should be suspected or taken into consideration. ${ }^{82}$

H) The association of down's syndrome (DS) and thyroid is well recognized with patients of DS have an increased prevalence of both $\mathrm{CH}$ and acquired thyroid function. ${ }^{83,84}$ Earlier studies reported that frequency of $\mathrm{CH}$ was 28times higher than in general population. ${ }^{84}$ Cebeci et al ${ }^{85}$ studied 62 patients with DS (32 male and 30 female) retrospectively from hospital records of patients with DS and hypothyroidism. They found a high prevalence of thyroid dysgenesis in patients with DS and hypothyroidism and advised further studies as no such previous association had been reported. ${ }^{85}$

I) Hypothyroidism induced reversible kidney dysfunction has been reported in three cases with 2 males 68 and $72 \mathrm{yrs}$ with serum creatinine and TSH being elevated to $1.4-3 \mathrm{mg} / \mathrm{dl}$ and 94-181miu/1 along with low free thyroxine levels (undetected to $0.4 \mathrm{ng} / \mathrm{dl}$ ). Initiation of increased doses of levothyroxine led to return of serum creatinine to baseline in several months (2-10mths), concluding a reversible relationship between thyroid gland and kidney function which maybe missed if the interplay is not kept in mind. ${ }^{86}$ This can be explained by the findings of Tsuda et al. ${ }^{87}$ suggesting low thyroid function even within normal range is associated with reduced renal plasma flow (RPF), regional blood flow (RBF) and glomerular filtration rates (GFR) which might be caused by a preferential increase in vascular resistance in the afferent arteriole (Ra). This conclusion was on the basis of studying 26 patients with serum creatinine $<1 \mathrm{mg}$ and without thyroid disease and on basis of serum TSH was positively correlated with Ra but not at the efferent arteriole (Re). Serum TSH was significantly and negatively correlated with TPF, RBF and GFR and in multiple regression analysis TSH was significantly positively associated with $\mathrm{Ra}$ after adjustment for age and mean $\mathrm{BP} .^{87}$
J) In a 20year period a single centre retrospective study Klose M emphasized the importance of improved awareness of thyroid status and optimal thyroid replacement of hypo pituitary patients to reduce cardiovascular risk in hypo pituitary patients with secondary hypothyroidism, irrespective of age, gender and IGF1 status. ${ }^{88}$

K) Childhood acute lymphoblastic leukemia (ALL) treated with chemotherapy alone present with hyperthyrotropinemia without antithyroid antibodies with a prevalence comparable to the control group as shown by Delvecchio et al. ${ }^{89}$ after study of 84 cases of ALL and concluded that a thyroid follow up in all off therapy as thyroid gland seems to be more prone to be damaged by chemotherapy at a younger age and it should be differentiated on the basis of age at the end of treatment with more frequent tests in younger patients. ${ }^{89}$

\section{Subclinical Hypothyroidism (SH)}

Subclinical hypothyroidism ( $\mathrm{SH})$ is an asymptomatic condition defined by increased serum TSH with serum free T4 and free T3 levels within their respective reference range. The treatment and management of SCTD and population screening are controversial despite potential risk of progression to overt disease. It can have repercussions on the cardiovascular system and bone as well as on other organs and systems. ${ }^{90}$ The prevalence has been reported to be between 4 and $20 \%$ of adult population ${ }^{91}$ and $1.7 \%$ in US children. ${ }^{92}$ It seems to be a benign remitting condition in childhood with a low risk of progression to overt hypothyroidism. A slight increase in TSH levels with normal TH's maybe transient and sometimes causes a false positive at neonatal screening for $\mathrm{CH} \cdot{ }^{93}$ The most frequent cause of persistent $\mathrm{SH}$ in childhood is represented by autoimmune thyroiditis. However iodine deficiency, obesity, non thyroid chronic diseases or inherited syndromes may also be responsible for mild increase in TSH levels. Mutations in genes encoding proteins involved in TSH pathway are thought to be involved in some cases of idiopathic $\mathrm{SH}$, particularly in familial setting. ${ }^{94-96}$

TSH exerts its activity by binding to the extracellular domain of TSHR. TSHR is a member of the G protein-coupled receptor family, which also includes calcitonin or PTH receptors. Cerbone et al. ${ }^{97}$ reported non autoimmune $\mathrm{SH}$ in 2 brothers carrying the same mutation in the extracellular domain of TSH-R but presenting with different clinical, biochemical and morphological features. The first one had only a slight persistent elevation of TSH, abnormal thyroid on ultrasound and did never require 1-thyroxine (L-T4) replacement treatment and had a normal IQ of 108 at age 16. The second one has a neonatal persistent moderate TSH levels increase associated with a thyroid gland hypoplasia and was treated with L-T4 since the first months of life although had an IQ of 80 at age 16, possibly due to initial low dosage/delay in starting treatment which its known to be associated with such outcomes..$^{97}$ The mutation R109Q in the extracellular domain of TSH-Xr, found in these 2 brothers was described by Clifton-Bligh et al in a child with compound heterozygous for another missense mutation in the fourth transmembrane segment of receptor. ${ }^{98}$ In the 2 siblings reported by Nicoletti et al. ${ }^{95}$ having the same R109Q mutation, milder phenotype was found, characterized by slight increase in serum TSH, normal thyroid gland at ultrasound and no clinical features of thyroid dysfunction. ${ }^{95}$

Rapa et al. ${ }^{99}$ evaluated the clinical characteristics and TSH-R gene variants in children with mild to moderate elevations of TSH with normal TH due to nonautoimmune SH. TSHR gene non-synonymous 
mutations/polymorphisms were found in $21.5 \%$ cases. ${ }^{99}$ Cerbone et al. ${ }^{100}$ studying 47 caucasian children ( 25 males) with long term idiopathic $\mathrm{SH}$ found that persistent $\mathrm{SH}$ in children is not associated with alteration in growth, bone maturation, BMI, and cognitive function or other complaints that could be attributed to SH even after several years without therapeutic intervention. ${ }^{100}$ In further extension of this study their group found no effect on bone health as evaluated by lumbar spine dual X-ray absorptiometry (DXA) and phalangeal quantitative ultrasound (QNS) as revealed by a study of 25 caucasian children and adolescents (11 males age 9.8+/-3yrs) and from their data concluded that QUS are comparable to those provided by DXA and QUS may represent a good, cheaper and safer screening test for bone evaluation in children with $\mathrm{SH} .{ }^{101}$ There is no clear cut benefit of L-thyroxine therapy in adults or children. ${ }^{102,103}$ Sunbul et al. ${ }^{104}$ found untreated SH is associated with impairment in left ventricular longitudinal myocardial function by two dimensional speckle trafficking echocardiography.

On studying 23 consecutive $\mathrm{SH}$ (both treated and untreated $\mathrm{SH}$ with 7 males in each group and controls all around 40years), they concluded that speckle tracking echocardiography appears to be useful both for early detection of left ventricular impairment in patients with $\mathrm{SH}$ and documentation of improvement in myocardial deformation parameters with treatment. ${ }^{104} \mathrm{Although}$ a prevalence of the minor allele of phosphodiesterase 8B (PDE8B) gene polymorphism associated with elevated serum levels of TSH was demonstrated in patients affected by sporadic nonautoimmune $\mathrm{SH}$, significant differences in circulating TSH in patients with minor or major alleles for each polymorphism were not identified demonstrating a lack of association between the polymorphisms and serum TSH levels in these 58 patients studied. ${ }^{105}$ Despite the negative impact of SH on CVS in young adults $(<55-60 \mathrm{yrs})$ the decision to treat elderly people still remains an unresolved clinical challenge dueto1) a lack of appropriately powered RCT of L-T4 in SH patients examining cardiovascular hard endpoints in various classes of age and 2 nd because of the negative effects of possible overtreatment in moderately old (70-75 and oldest old $>85$ yrs. ${ }^{106}$

\section{Role in male reproduction}

Velasquez \& Arata $^{107}$ found no changes in free testosterone (T) levels in hypothyroid men, whereas several other studies have shown a fall in circulating $\mathrm{T}$ levels in hypothyroid patients. ${ }^{108,109}$ Velasquez and Arata found a rise in only FSH without a concomitant rise in LH levels, whereas Jaya Kumar found a rise in both serum FSH as well as LH levels. ${ }^{109}$ However Donnelly and White found no changes in either serum FSH/LH levels in hypothyroid men. ${ }^{109} \mathrm{GnRH}$ administration to hypothyroid patients resulted in attenuated LH responses. ${ }^{110}$ In hypothyroid males Morris et al. ${ }^{11}$ found as significant decrease in gonadal steroids, namely, progesterone $(\mathrm{P})$, and total $\mathrm{T}$. Bioavailable $\mathrm{T}$ (Bio T), calculated by Morris's formula was reduced in hypothyroid men. Morris et al. ${ }^{111}$ measured serum total T, SHBG by ELISA, BioT by Tremblay and Dude method, ${ }^{112}$ calculated percent free $\mathrm{T}$ and free $\mathrm{T}$ by Nanjee's formula ${ }^{113}$ and Vermulelen's computer ${ }^{114}$ respectively. On the basis of these calculations, they developed and validated an equation for calculation of Bio T. On this basis they concluded that total $\mathrm{T}$ has the best predictor of Bio $\mathrm{T}$. They proposed the following for the cause of fall in T:

a. Low cholesterol uptake in Leydig cells as evident from high serum cholesterol levels

b. Lower conversion of progesterone $(\mathrm{P})$ to $\mathrm{T}$ as evidenced by low $\mathrm{T} / \mathrm{P}$ ratio c. Higher conversion of estradiol (E2) to T as suggested by high E2:T ratio and

\section{d. Hyperprolactinaemia.}

High prolactin suppresses $17 \alpha$-hydroxylase enzyme in rat testicular cells which catalyzes the conversion of P to $17 \alpha$ hydroxyl P. ${ }^{115}$ Although this raised a question about the role of $\mathrm{T}$ on the feedback inhibition of pituitary gonadotropin release, ${ }^{116,117}$ in studies of Kumar et al., ${ }^{117}$ serum E2 levels were similar in hypothyroid as well euthyroid men, which suggested that E2 is the prime regular of negative feedback on pituitary level of gonadotropins, instead of $\mathrm{T}$ as has been corroborated by studies by Rochira et al. ${ }^{118,119}$ They showed that basal and GnRH stimulated LH and FSH secretion was higher than normal in aromatase deficient men with normal $\mathrm{T}$ levels. Rochira et al., ${ }^{118}$ reported 4 cases of tall stature without growth hormone deficiency who had a impaired response of GH to GHRHARG as compared to normal subjects and who had significantly lower IGF1 levels as compared to normal subjects and both IGF1 peak and concentrations were not modified by estrogen therapy in men with aromatase deficiency and concluded insulin as the cause of tall stature rather than $\mathrm{GH}$ for the marked increase in height due to nonclosure of epiphyses. ${ }^{120}$ Besides that for normal physiology, Pitteloud et al., ${ }^{121}$ showed that for Inhibition of LH secretion by T in men aromatization is required for its pituitary effect but not its hypothalamic effect as shown by studying 11 men with GnRH deficenicy normal (NL). ${ }^{121,122}$

\section{Discussion and interpretations}

Although it is clear that $\mathrm{AH}$ is 4times more common in females the particular type of $\mathrm{AH}$, namely IgG4 related thyroiditis, which appears to be associated with male hypothyroidism is a more aggressive form of HT. As for $\mathrm{CH}$, with the NNSP now in most countries it is a crime to have any case presenting with cretinism in adulthood and although the prevalence of female: male $\mathrm{CH}$ varies from 2:1,1:1,1:1.4 from various geographical regions, a screening programme for every child has become essential rather than excluding male children thinking of low incidence of hypothyroidism in males with the idea of eradicating cretinism from globe in view of the essential role of thyroid hormone in the development of various important organ systems.

Central Hypothyroidism $(\mathrm{CeH})$ is generally a H-P disorder, where IGSF1 has been noted to be an important $\mathrm{X}$ linked disorder as a cause of $\mathrm{CeH}$ and affecting male hypothyroidism as well as reproduction. Other rare disorders which can present with $\mathrm{CeH}$ can be APS, deletion in Thyrotropin $\beta$ subunit, heterozygous mutations with FGF8, with thalassemia major and more rarely as long with stage IV small Cell Carcinoma. Neurological complications include extreme presentation with coma where patients may/may not respond to levothyroxine therapy, where steroid therapy may be of help. Thus high index of suspicion should be kept when a male patient presents unconscious without any known cause. Other manifestations include neuropathies and myopathies of which stiff person syndrome, Hoffmann syndrome have been the common manifestations and presenting complaints in variable manner in males having hypothyroidism of untreated hypothyroidism of long term origin which responds to therapy with TH. Hypothyroidism maybe the presenting complaint of multiple autoimmune syndromes like chromosome $18 \mathrm{p}$ syndrome, associated with ulcerative colitis, be part of a polyendocrinopathy syndrome. Obesity has also been correlated with thyroid autoimmunity and the explanation of how excessive iodine use is linked to thyroid autoimmunity has finally been explained by Latrofa et al., ${ }^{75}$ who explained iodine induced thyroid autoimmunity is related to $\mathrm{TgAb}$ and 
the unmasking of cryptic epitope on $\mathrm{Tg}$ contributes to this relationship in humans. ${ }^{75}$ Other miscellaneous disorders like consumptive hypothyroidism, EIA, OSA can present with hypothyroidism, or as complications following patients who have been on ATT (specifically PAS and PAS with ethionamide), treatment for ALL. Recently it has been emphasized that hypothyroidism induced reversible kidney function gets corrected just by treating hypothyroidism. No effect of persistent SH in children was found in growth, bone maturation, BMI, cognitive function or other complaints that could be attributed to untreated SH even after several years without therapeutic intervention, suggesting no need of therapy in children with SH. However in young adults some effect on left ventricular function suggested which warrants treatment. Thus despite effect on CVS function the decision to treat $\mathrm{SH}$ in elderly remains unresolved because of fear of over treating in moderately old and oldest of old. As far as reproduction is concerned both primary hypothyroidism should be considered as a cause of $\mathrm{HH}$, and $\mathrm{SH}$ needs to be treated in infertile males with the known effects on sperm motility, morphology parameters ${ }^{123,124}$ as well as effects on gonadal hormones as well as serum prolactin.

\section{Conclusion}

Although hypothyroidism is common in females it may be the primary cause of male $\mathrm{HH}$ especially $\mathrm{CeH}$ and should be looked for in a man with delayed puberty as a primary cause with importance of IGSF highlighted recently. Also untreated hypothyroidism may be the cause of presentation as myopathies like Hoffmann's syndrome or other myopathic syndromes. Subclinical hypothyroidism in young males may warrant treatment with the known adverse affects on cardiovascular system in young males although its effects on cognitive function has not been found especially in old age. ${ }^{125}$

\section{Acknowledgements}

None.

\section{Conflict of interest}

Author declares that there is no conflict of interest.

\section{References}

1. Li Y, Nishihara E, HirokawaM, et al. Distinct clinical, serological and sonographic characteristics of Hashimoto's thyroiditis based with and without IgG4-positive plasma cells. J Clin Endocrinol Metab. 2010;95(3):1309-1317.

2. Salook MA, Benbassat C, Strenov Y, et al. IgG4-related thyroiditis: a case report and review of literature. Endocrinol Diabetes Metab Case Rep. 2014;2014:140037.

3. Toublanc JE. Comparison of epidemiological data on congenital hypothyroidism in Europe with those of other parts in the world. Horm Res. 1992;38(5-6):230-235.

4. Devos H, Rodd C, Gagne N, et al. A search for the possible molecular mechanisms of thyroid dysgenesis: sex ratios and associated malformations. J Clin Endocrinol Metab. 1999;84(7):2502-2506.

5. Fisher DA. Clinical Pediatrics Endocrinology. In: Kaplan SA, editor. The Thyroid. Philadelphia, Pennsylvania: WB Saunders Company; 1990. p. $87-126$.

6. Fisher DA. Second International Conference on Neonatal Thyroid Screening: progress report. J Pediatr. 1983;102(5):653-654.

7. Harris KB, Pass KA. Increase in congenital hypothyroidism in New York State in the United States. Mol Genet Metab. 2007;91(3):268-277.
8. La Franchi SH, Murphey WH, Foley TP, et al. Neonatal hypothyroidism detected by the Northwest Regional Screening Program. Pediatrics. 1979;63(2):180-191.

9. Dilli D, Ozbas S, Acican D, et al. Establishment and Development of a National Newborn Screening Programme for Congenital Hypothyroidism in Turkey. J Clin Res Pediatr Endocrinol. 2013;5(2):73-79.

10. Zenalzadeh AH, Talebi M. Neonatal screening for congenital hypothyroidism in East Azerbaijan, Iran: the first report. $J$ Med Screen. 2012;19(3):123-126.

11. Nair PS, Kumar SS, Kailas L. Diagnostic re-evaluation of Children with Congenital Hypothyroidism. Indian Pediatr. 2010;47(9):757-760.

12. Bekhit OE, Yousef RM. Permanent and Transient Congenital Hypothyroidism in Fayoum, Egypt: a Descriptive Retrospective Study. PLoS One. 2013;8(6):e68048.

13. Oedookhani A, Mirmiran P, Moharamzadeh M, et al. A high prevalence of consanguineous and severe congenital hypothyroidism in an Iranian population. J Pediatr Endocrinol Metab. 2004;17(9):1201-1209.

14. Tonacchera M, Banco M, Lapi P, et al. Genetic analysis of TTF-2 gene in children with congenital hypothyroidism and cleft palate, congenital hypothyroidism or isolated cleft palate. Thyroid. 2004;14(8):584-588.

15. Constanet M, Polak M, Bonaiti PC, et al. Nineteen years of national screening for congenital hypothyroidism: Familial cases with thyroid dysgenesis suggest the involvement of genetic factors. $J$ Clin Endocrinol Metab. 2001;86(5):2009-2014.

16. Srivastav A, Maisnam I, Dutta D, et al. Cretinism revisited. Indian J Endocrinol Metab. 2012;16(Suppl 2):336-337.

17. Eastman CJ , Zimmermann M. Chapter 20 The iodine deficiency disorders. Thyroid Disease Manager. South Dartmouth, Massachusetts, USA; 2014.

18. Salerno T, Peca D, Menchini L, et al. Respiratory insufficiency in a newborn with congenital hypothyroidism due to a new mutation of TTF1/NKX2.1 gene. Pediatr Pulmonol. 2014;49(3):42-44.

19. Sandal G, Pirgon O, Ormeci AR. Bamforth syndrome: is porencephaly a new finding? Genet Couns. 2013;24(3):279-282.

20. Altmann K, Hermanns P, Muhlenberg R, et al. Congenital goitrous primary hypothyroidism in two German families caused by novel thyroid peroxidase (TPO) gene mutations. Exp Clin Endocrinol Diabetes. 2013;121(6):343-346.

21. Agretti P, DeMarco G, Di Cosmo C, et al. Congenital hypothyroidism caused by a novel homozygous mutation in thyroglobulin gene. Eur $J$ Pediatr. 2013;172(7):959-964.

22. Moia S, Godi M, Walker GE, et al. The W520X mutation in the TSHR gene brings on subclinical hypothyroidism through an haploinsufficiency mechanism. J Endocrinol Invest. 2013;36(9):716-721.

23. Vincenzi M, Canilot Y, Ferrarini F, et al. Identification of a nove pax8 gene variant in four members of the same family: from Congenital hypothyroidism with thyroid hypoplasia to mild subclinical hypothyroidism. BMC Endocr Disord. 2014;14:69.

24. Kuhnen P, Turan S, Frohler S, et al. Identification of PENDRIN (SLC26A4) mutations in patients with congenital hypothyroidism and "apparent" thyroid dysgenesis. J Clin Endocrinol Metab. 2014;99(1):169-176.

25. Montanelli L, Agretti P, Marco Gd, et al. congenital hypothyroidism and late-onset goiter: identification and characterization of a novel mutation in the sodium/iodide symporter of the proband and family members. Thyroid. 2009;19(12):1419-1425 
26. Horn S, Heuer H. Thyroid hormone action during brain development: more questions than answers. Mol Cell Endocrinol.2010;315(1-2):19-26.

27. DeLong GR, Stanbury JB, Benitez FR. Neurological signs in congenital iodine deficiency disorder(endemic cretinism). Dev Med Child Neurol. 1985;27(3):317-324.

28. Klein AH, Meltzer S, Kenny FM. Improved prognosis in congenital hypothyroidism treated before three months. J Pediatr. 1972;81(5):912-915.

29. Gruters A, Jenner A, Krude H. Long term consequences of congenital hypothyroidism in the era of screening programmes. Best Pract Res Clin Endocrinol Metab. 2002;16(2):369-382.

30. Huffmeier U, Teitze HU, Rauch A. Severe skeletal dysplasia caused by undiagnosed hypothyroidism. Eur J Med Genet. 2007;50(3):209-215.

31. Delvecchio M, Faienza MF, Acquafredda A, et al. Longitudinal assessment of levo-thyroxine therapy for congenital hypothyroidism; relationship with aetiology, bone maturation and biochemical features. Horm Res. 2007;68(3):105-112.

32. Delvecchio M, Salerno M, Acquafredda A, et al. Factors predicting final height in early treated congenital hypothyroid patients. Clin Endocrinol. 2006;65(5):693-697.

33. Niu DM, Hwang B, Tiu CM, et al. Contributions of bone maturation measurements to the differential diagnosis of neonatal transient hypothyroidism versus dyshormogenetic congenital hypothyroidism. Acta Paediatr. 2004;93(10):1301-1306.

34. Lichtenberger GL, Dos Santos S, Hassani Y, et al. Factors associated with hearing impairment in patients with congenital hypothyroidism treated since the neonatal period: a neonatal population based study. $J$ Clin Endocrinol Metab. 2013;98(9):3644-3652.

35. Albert BB, Heather N, Derraik JG, et al. Neuro developmental and body composition outcomes in children with congenital hypothyroidism treated with high dose initial replacement and close monitoring. J Clin Endocrinol Metab. 2013;98(9):3663-3670.

36. Schokking JJB, Resing WC, de Rijke YB, et al. Cognitive development in congenital hypothyroidism: is overtreatment a greater threat than undertreatment? J Clin Endocrinol Metab. 2013;98(11):4499-4506.

37. Bagattini B, Cosmo CD, Montanelli L, et al. The different requirement of L-T4 therapy in congenital athyreosis compared with adult acquired hypothyroidism suggests a persisting thyroid hormone resistance at the hypothalamic-pituitary level. Eur J Endocrinol. 2014;171(5):615-621.

38. Oliviero U, Cittadini A, Bosso A, et al. Effects of long term L-thyroxine treatment on endothelial function and arterial distensibility in young adults with congenital hypothyroidism. Eur $J$ Endocrinol. 2010;162(2):289-294.

39. Dutta D, Maisnam I, Ghosh S, et al. Panhypopituitarism with empty sella a sequel of pituitary hyperplasia due to chronic primary hypothyroidism. Indian J Endocrinol Metab. 2012;16(Supp12):S282-284.

40. Joustra SD, Schoenmakers N, Persani L, et al. The IGSF 1 Deficiency Syndrome :Characteristics of Male and Female Patients. J Clin Endocrinol Metab. 2013;98(12):4942-4952.

41. Nakamura A, Bak B, Silander TL, et al. Three novel IGSF1mutations in four Japanese patients with X-linked congenital central hypothyroidism. J Clin Endocrinol Metab. 2013;98(10):E1682-1691.

42. Cayir A, Tasdemir S, Eroz R, et al. Anophthalmia-plus syndrome with unusual findngs . A clinical report and review of the literature. Genet Couns. 2013;24(3):307-312.

43. Hermanns P, Couch R, Leonard N, et al. A novel Deletion in the Thyrotropin Beta subunit Gene Identified by Array Comparative Genomic Hybridization Analysis causes Central Congenital Hypothyroidism in a boy originating from Turkey. Horm Res Paediatr. 2014;82(3):201-205.
44. Suzuki E, Yatsuga S, Igarashi M, et al. De novo Frameshift Mutation in Fibroblast Growth Factor 8 in a male patient with gonadotropin deficiency. Horm Res Pediatr. 2013;81(2):139-144.

45. Gruenwald S, Caron P. Central hypothyroidism in adults: better understanding for better care. Pituitary [Epub ahead of print]. 2015;18(1):169-75.

46. Soliman AT, Al Yafei F, Al-Naimi L, et al. Longitudinal study on thyroid function in patients with thalassaemia major: high incidence of central hypothyroidism by 18 years. Indian J Endocrinol Metab. 2013;17(6):1090-1095.

47. Shah KK, Anderson RJ. Acute secondary adrenal insufficiency as the presenting manifestation of small cell lung carcinoma. BMJ Case Rep. 2014.

48. Sesazawa DT, Tsukomo SM, Lalli CA. Myxedema coma in a patient with type 1 neurofibromatosis: rare association. Arq Bras Endocrinol Metabol. 2013;57(9):743-747.

49. Williams A, Green N, Phyu CT, et al. A case of newly diagnosed primary hypothyroidism with deteriorating consciousness that did not respond to thyroxine-what else should be considered? Acute Med. 2013;12(2):102-104

50. Mir SA, Wani AI, Masoodi SR, et al. Lithium toxicity and myxedema crisis in an elderly patient. Indian $J$ Endocrinol Metab. 2013;17(Suppl3):654-656.

51. Bauer M, Silverman DH, Schlagenhauf F, et al. Brain glucose metabolism in hypothyroidism: a positron emission tomography study before and after thyroid hormone replacement therapy. J Clin Endocrinol Metab. 2009;94(8):2922-2929.

52. Gupta KJ. Myxedema coma: a sleeping giant in clinical practice. Am J Med. 2013;126(12):e3-4.

53. Sowmini PR, Jawahar M, Bhanu K. Uncommon presentation of a common disorder. Ann Indian Acad Neurol. 2013;16(1):111-113.

54. Udayakumar N, Rameshkumar AC, Srinivasan AV. Hoffmann syndrome: presentation in hypothyroidism. J Postgrad Med. 2005;51(4):332-333.

55. Benvenga S, Toscano A, Rodlico C, et al. Endocrine evaluation for muscle pain. J R Soc Med. 2001;94(8):405-407.

56. Mastaglia FL. Skeletal Muscle Pathology. Churchill Livingstone, Philadelphia, USA: Endocrine myopathies. 1992.

57. Vasconcellos LF, Peixoto MC, Oliveira TND, et al. Hoffmann syndrome: pseudohypertrophic myopathy as initial manifestation of hypothyroidism. Case report. Arq Neuropsiquiatr. 2003;61(3B):851-854.

58. Aleem MA, Paramasivam M, Samson TA. Hoffmann Syndrome. J Assoc Physicians India 2004;52:889.

59. Senanayake HM, Dedigama AD, Alwis RP, et al. Hoffmann Syndrome: a case report. Int Arch Med. 2014;7(1):2.

60. Cebeci AN, Guven A, Saltik S, et al. Hoffmann's syndrome and pituitary hyperplasia in an adolescent secondary to Hashimoto thyroiditis. $J$ Pediatr Endocrinol Metab. 2013;26(7-8):747-751.

61. Nalini A, Govindaraju C, Kalra P, et al. Hoffmann's syndrome with unusually long duration: Report on clinical, laboratory and muscle imaging finding in two cases. Ann Indian Acad Neurol. 2014;17(2):217-221.

62. Cetinakaya DD, Demirpence MM, Gorgel A, et al. A rare Association of monosomy 18p Syndrome and polyglandular Autoimmune syndrome Type IIIA. Balkan J Med Genet. 2013;16(1):81-84.

63. Najafi M, Zamani MM, Rezaei N, et al. Autoimmunity in inflammatory bowel disease : a case of ulcerative colitis with diabetes mellitus, autoimmune hepatitis, and autoimmune hypothyroidism. Turk J Pediatr. 2012;54(6):651-653 
64. Kharb S, Gundgurthi A, Dutta MK, et al. Reversible adrenal insufficiency and heterophile antibodies in a case of autoimmune polyendocrinopathy syndrome. Indian J Endocrinol Metab. 2013;17(Suppl3):S700-702.

65. Duntas LH, Biondi B. The interconnections between obesity, thyroid function, and autoimmunity: the multifold role of leptin. Thyroid. 2013;23(6):646-653.

66. Rotondi M, Leporati P, Rizza MI, et al. Raised serum TSH in morbidobese patients: effects on the circulating lipid profile. Endocrine. 2014;45(1):92-97.

67. Misra S, Singh S. Insulin resistance and hypothyroidism: a complex relationship in nonalcoholic fatty liver disease. J Indian Med Assoc. 2013;111(5):324-329.

68. Posedas RC, Jorge GE, Acuna VJ, et al. Fatty liver largely explains associations of subclinical hypothyroidism with insulin resistance, metabolic syndrome, and subclinical coronary atherosclerosis. Eur $J$ Endocrinol. 2014;171(3):319-325.

69. Zhang Y, Kim BK, Zhang Y, et al. Thyroid hormones and coronary artery calcification in euthyroid men and women. Arterioscler Thromb Vasc Biol. 2014;34(9):2128-2134.

70. Dahiya S, Verma M, Dhankar R, et al. Alteration of ischemia modified albumin and nitric oxide levels in hypothyroidism. Clin Lab 2014;60(6):969-977.

71. Wolff J, Chaikoff IL, Goldberg RC, et al. The temporary nature of the inhibitory action of excess iodine synthesis in the normal thyroid gland. Endocrinology. 1949;45(5):504-513.

72. Wolff J, Chaikoff IL. Plasma inorganic iodine as a homeostatic regulator of thyroid function. J Biol Chem. 1948;174(2):555-564.

73. Pitsiavas V, Smerdely P, Boyages SC. Amiodarone compared with iodine exhibits a potent and persistent inhibitory effect on TSH-stimulated cAMP production in vitro: A possible mechanism to explain amiodarone induced hypothyroidism. Eur J Endocrinol. 1999;140(3):241-249.

74. Theodoropoulous T, Braverman LE, Vagenakis AG. Iodine-induced hypothyroidism: A potential hazard during perinatal life. Science. 1979;205(4405):502-503.

75. Latrofa F, Fiore E, Rago T, et al. Iodine contributes to thyroid autoimmunity in humans by unmasking a chronic epitope on thyroglobulin. $\mathrm{J}$ Clin Endocrinol Metab. 2013;98(11):1768-1774.

76. De Corti F, Crivellaro C, Zanori GF, et al. Consumptive hypothyroidism associated with parotid infantile hemangioma. J Pediatr Endocrinol Metab. 2015; 28(3-4):467-9.

77. Turan E, Cimen V, Haytoglu NSK, et al. A case of bullous erythema ab igne accompanied by anemia and subclinical hypothyroidism. Dermatol Online J. 2014;20(4):22336.

78. Araz O, Yilmazel UE, Yalcin A, et al. The incidence and severity of pulmonary hypertension in obstructive sleep apnea with hypothyroidism. Med Sci Monit. 2013;19:883-887.

79. Andries A, Isaakidis P, Das M, et al. High rate of hypothyroidism in multidrug-resistance tuberculosis patients co-infected with HIV in Mumbai, India. PloS One. 2013;8(10):e78313.

80. Hadlow NC, Rothacker KM, Wardrop R, et al. The relationship between $\mathrm{TSH}$ and free T4 in a large population is a complex and nonlinear and differs by age and sex. J Clin Endocrinol Metab. 2013;98(7):2936-2943.

81. Dayal D, Bhalla AK, Sachdeva N. A boy with prepubertal gynecomastia, hyperprolactinemia, and hypothyroidism. $J$ Pediatr Endocrinol Metab. 2013;26(3-4):357-360.

82. Krysiak R, Okopien B. Methyltestosterone-induced transient hyperthyroidism in a hypothyroid patient. Acta Clin Belg 2013;68(1):65-67.
83. Pueschel SM, Pezzullo JC. Thyroid dysfunction in Down syndrome. Am J Dis Child. 1958;139(6):636-639.

84. Fort P, Lifshitz F, Bellisario R, et al. Abnormalities of thyroid function in infants with Down's syndrome. J Pediatr. 1984;104(4):545-549.

85. Cebeci AN, Guven A, Yildiz M. Profile of hypothyroidism in Down's syndrome. J Clin Res Pediatr Endocrinol. 2013;5(2):116-120.

86. El Ters M, Patel SM, Norby SM. Hypothyroidism and reversible kidney dysfunction: An essential Relationship to recognize. Endocr Pract 2014;20(5):490-499

87. Tsuda A, Inaba M, Ichii M, et al. Relationship between serum TSH levels and intrarenal hemodynamic parameters in euthyroid subjects. Eur $J$ Endocrinol. 2013;169(1):45-50.

88. Klose M, Marina D, Nielsen MLH, et al. Central hypothyroidism and its replacement have significant influence on cardiovascular risk factors in adult hypopituitary patients. $J$ Clin Endocrinol Metab. 2013;98(9):3802-3810.

89. Delvecchio M, Cecinati V, Brescia LP, et al. Thyroid function and thyroid autoimmunity in childhood acute lymphoblastic leukaemia off therapy patients treated only with chemotherapy. J Endocrinol Invest. 2010;33(3):135-139

90. Biondi B, Cooper DS. The clinical significance of subclinical thyroid dysfunction. Endocr Rev. 2008;29(1):76-131.

91. Biondi B. Natural history, diagnosis and management of subclinical thyroid dysfunction. Best Pract Res Clin Endocrinol Metab. 2012;26(4):431-446

92. Wu T, Flowers JW, Tudiver F, et al. Subclinical thyroid disorders and cognitive performance among adolescents in the Unites States. BMC Pediatr. 2006;6:12.

93. Leonardi D, Polizzotti N, Carta A, et al. Longitudinal study of thyroid function in children with mild hyperthyrotropinemia at neonatal screening for congenital hypothyroidism. J Clin Endocrinol Metab. 2008;93(7):2679-2685

94. Arrigo T, Wasniwska M, Ceisafulli G, et al. Subclinical hypothyroidism: the state of art. J Endocrinol Invest. 2008;31(1):79-84.

95. Nicoletti A, Bal M, De Marco G, et al. Thyrotropin-stimulating hormone receptor gene analysis on pediatric patients with nonautoimmune subclinical hypothyroidism. J Clin Endocrinol Metab. 2009;94(11):4187-4194

96. Alberti L, Proverbio MC, Costagliola S, et al. Germline mutations of TSH receptor gene as cause of non-autoimmune subclinical hypothyroidism. $J$ Clin Endocrinol Metab. 2002;87(6):2549-2555.

97. Cerbone M, Agretti P, DeMarco G, et al. Non autoimmune subclinical hypothyroidism due to a mutation in TSH receptor: report on two brothers. Ital J Pediatr. 2013;39:5.

98. Clifton-Bligh RJ, Gregory JW, Ludgate M, et al. Two novel mutations in the thyrotropin (TSH) receptor gene in a child with resistance to TSH. $J$ Clin Endocrinol Metab. 1997;82(4):1094-1100.

99. Rapa A, Monzani A, Moia S, et al. Subclinical hypothyroidism in children and adolescents: a wide range of clinical, biochemical, and genetic factors involved. J Clin Endocrinol Metab. 2009;94(7):2414-2420.

100. Cerbone M, Bravaccio C, Capalbo D, et al. Linear growth and intellectual outcome in children with long-term idiopathic subclinical hypothyroidism. Eur J Endocrinol. 2011;164(4):591-597.

101. Di Mase R, Cerbone M, Improda N, et al. Bone health in children with longterm idiopathic subclinical hypothyroidism. Ital J Pediatr. 2012:38:56. 
102. Villar HC, Saconato H, Valente O, et al. Thyroid hormone replacement for subclinical hypothyroidism. Cochrane Database Syst Rev. 2007;18(3):CD003419.

103. Wasniewska M, Corrias A, Aversa T, et al. Comparitive evaluation of therapy with L-thyroxine versus no treatment in children with idiopathic and mild subclinical hypothyroidism. Horm Res Paediatr. 2012;77(6):376-381.

104. Sunbul M, Durmus E, Kivrak T, et al. Left ventricular strain and strain by two dimensional speckle tracking echocardiography in patients with subclinical hypothyroidism. Eur Rev Med Pharmaco Sci. 2013;17(24):3323-3328.

105. Agretti P, De Marco G, Di Cosmo C, et al. Frequency and effect on serum TSH of phosphodiesterase 8B (PDE8B) gene polymorphisms in patients with sporadic non-autoimmune subclinical hypothyroidism. $J$ Endocrinol Invest. 2014;37(2):189-194.

106. Pasqualetti G, Tognini S, Polini A, et al. Is subclinical hypothyroidism a cardiovascular risk factor in the elderly? J Clin Endocrinol Metab. 2013;98(6):2256-2266.

107. Velasquez EM, Arata GB. Effects of thyroid status on pituitary gonadotropin testicular reserve in men. Arch Androl. 1997;38(1):85-92.

108. Jaya KB, Khurana ML, Ammini AC, et al. Reproductive endocrine functions in men with primary hypothyroidism: effects of thyroxine replacement. Horm Res. 1990;34(5-6):215-218.

109. Donnelly P, White C. Testicular dysfunction in men with primary hypothyroidism: Reversal of hypogonadotropic hypogonadism with replacement thyroxine. Clin Endocrinol. 2000;52(2):197-201.

110. Prasanna kumar KM, Khurana ML, Ammini AC, et al. Pituitary response to luteinizing hormone releasing hormone in hypothyroidism. In: Vichanrat A, Nityanant W, Eastman C, editors. Recent Progress in Thyroidology. Crystal House, Bangkok, Thailand; 1987. p. 511-515.

111. Morris PD, Malkin CJ, Channer KS, et al. A mathematical comparison of techniques to predict biologically available testosterone in a cohort of 1072 men. Eur J Endocrinol. 2004;151(2):241-249.

112. Tremblay RR, Dube JY. Plasma concentrations of free and non TeBG bound testosterone in women on oral contraceptives. Contraception. 1974;10(6):599-605

113. Nanjee MN, Wheeler MJ. Plasma free testosterone-Is an index sufficient? Ann Clin Biochem. 1985;22(4):387-390.
114. Vermuelen A, VerdonekL, Kaufman JM. A critical evaluation of simple methods for the estimation of free testosterone in serum. $J$ Clin Endocrinol Metab. 1999;84(10):3666-3672.

115. Welsh TH, Kason BG, Hsueh AJ. Direct biphasic modulation of gonadotropin-stimulated testicular androgen biosynthesis by prolactin. Biol Reprod. 1986;34(5):796-804.

116. Kumar A, Chaturvedi PK, Mohanty BP. Hypoandrogenemia is associated with subclinical hypothyroidism in men. Int J Androl. 2006;30(1):14-20.

117. Kumar A, Mohanty BP, Rani L. Secretion of testicular steroids and gonadotropins in hypothyroidism. Andrologia. 2007;39(6):253-260.

118. Rochira V, Balestrieri A, Faustini-Fustini M, et al. Pituitary function in a man with congenital aromatase deficiency: Effect of different doses of transdermal E2 on basal and stimulated pituitary hormones. $J$ Clin Endocrinol Metab. 2002;87(6):2857-2862.

119. Rochira V, Zirilli L, Genazzani AD, et al. Hypothalamo-pituitarygonadal axis in two men with aromatase deficiency: Evidence that circulating estrogens are required at the hypothalamic level for the integrity of the gonadotropin negative feedback. Eur $J$ Endocrinol. 2006;155(4):513-522.

120. Rochira V, Zirilli L, Maffei L, et al. Tall stature without Growth hormone: Four male patients with aromatase deficiency. J Endocrinol Metab. 2010;95(4):1626-1633.

121. Pitteloud N, Dwyer AA, De Cruz S, et al. Inhibition of luteinizing hormone secretion by testosterone in men requires aromatization for its pituitary but not its hypothalamic effects: evidence from tandem study of normal and gonadotropin-releasing hormone-deficient men. J Clin Endocrinol Metab. 2008;93(3):784-791.

122. Kochar KK, Alaahbadia GN, Singh M. Male hypogonadism-A review of secondary hypogonadism with special emphasis on hypogonadotropic hypogonadism. J Endocrinol, Diabetes \& Obesity. 2014;2(2):1023.

123. Krassas GE, Papadopololou F, Tzimoalos K, et al. Hypothyroidism has an adverse eggect on human spermatogenesis: Aprospective, controlled study. Thyroid. 2008;18(12):1255-1259.

124. Hernandez JJC, Garcia MJM, Garcia-Diez LC. Primary hypothyroidism and human spermatogenesis. Arch Androl. 1990;25(1):21-27.

125. Wijsman LW, deCraenAJ, Trompet S, et al. Subclinical thyroid dysfunction and cognitive decline in old age. PLoS One. 2013;8(3):e59199. 